\title{
Characterisation of Cassava Bagasse and Composites Prepared by Blending with Low-Density Polyethylene
}

\author{
Fabiane Oliveira Farias ${ }^{1}$, Ariana Crasnhak Jasko ${ }^{1}$, Tiago André Denck Colman ${ }^{2}$, Luís \\ Antônio Pinheiro ${ }^{3}$, Egon Schnitzler ${ }^{2}$, Ana Cláudia Barana ${ }^{1}$ and Ivo Mottin Demiate ${ }^{1 *}$ \\ ${ }^{I}$ Departamento de Engenharia de Alimentos; Universidade Estadual de Ponta Grossa; Ponta Grossa - PR - Brasil. \\ ${ }^{2}$ Departamento de Química; Universidade Estadual de Ponta Grossa; Ponta Grossa - PR - Brasil. ${ }^{3}$ Departamento \\ de Engenharia de Materiais; Universidade Estadual de Ponta Grossa; Ponta Grossa - PR - Brasil.
}

\begin{abstract}
The main objective of this study was to characterise the cassava bagasse and to evaluate its addition in composites. Two cassava bagasse samples were characterised using physicochemical, thermal and microscopic techniques, and by obtaining their spectra in the mid-infrared region and analysing them by using $x$-ray diffraction. Utilising sorption isotherms, it was possible to establish the acceptable conditions of temperature and relative humidity for the storage of the cassava bagasse. The incorporation of cassava bagasse in a low-density polyethylene (LDP) matrix was positive, increasing the elasticity modulus values from 131.90 for LDP to 186.2 for $70 \%$ LDP with $30 \%$ SP bagasse. These results were encouraging because cassava bagasse could serve as a structural reinforcement, as well as having environmental advantages for its application in packaging, construction and automotive parts.
\end{abstract}

Key words: Manihot esculenta Crantz, residue, polymers

\section{INTRODUCTION}

Cassava (Manihot esculenta Crantz) is a key tropical crop that is grown in the tropical and subtropical areas in the world due to its excellent ability to adapt to different climatic and soil conditions and because it produces high yields of starch (Utsumi et al. 2012; Maieves et al. 2012; Rosenthal et al. 2012). Brazil was till recently the third largest world producer of cassava, with a production of 24 million tonnes, representing $10.5 \%$ of the global market of cassava roots (FAO 2010). Maieves et al. (2012) studied ten Brazilian cassava cultivars and found starch and total fiber contents ranging from 72.92 to $74.51 \%$ and from 4.70 to $7.12 \%$, respectively on dry basis. Differences in the chemical composition of cassava roots are related to genetic diversity, environmental conditions, and agricultural practices.

The processing of cassava roots for starch production generates residues, and the most abundant solid fraction is called bagasse, which is a fibrous, starchy, very moist material that results from the process (Teixeira et al. 2009; 2012). Cassava bagasse is a fibrous by-product containing around $50 \%$ of starch on dry weight basis (Maieves et al. 2011); for each ton of fresh roots when processed, another ton of cassava bagasse (85\% moisture) is produced (Pandey et al. 2000). The moisture content of the bagasse when it leaves the processing is very high, around $85 \%$, which makes it difficult to store and transport; the material consequently has a very high level of perishability. Its dry matter contains starch and fibrous compounds in almost equivalent

*Author for correspondence: demiate@uepg.br 
proportions, with low levels of minerals, proteins and lipids that together make up less than $5 \%$ on dry basis (Teixeira et al. 2009).

Natural fibres are valued in many industrial fields due to the fact that are renewable, biodegradable and, in many cases could be a sustainable way of production. In Brazil, there are numerous natural sources of fibre, such as those from banana, coir, cotton, pineapple, sisal, sugar cane, coconut, etc. There are several studies about their properties and applications (Satyanarayana et al. 2007). As an example of the utilisation of natural fibre in industrial products, Ashori (2008) published a review of wood-plastic composites and their importance for the automotive industry as promising 'green' composites with both the ecological and technical advantages of vegetable fibres to reinforce polymers. The article emphasised the possibility of improvement in mechanical strength and acoustic performance, the reduction of material weight and fuel consumption, lower production costs and biodegradability. Other advantages associated with the bio-composites include improved impact resistance and heat re-formability, with a cost less than that of comparable products made from plastics alone (Ashori and Nourbakhsh 2009). Composites reinforced with natural fibre blends have shown enhanced tensile and flexural properties, with higher mechanical properties than nylon 6 (suitable for automotive application especially under-hood applications), indicating the potential use of natural fibre blends for specific uses in the automobile industry (Ozen et al. 2013).

According to Akil et al. (2011), vegetable fibres include bast fibres (or sclerenchyma), leaf or hard fibres, seeds, fruit, wood, cereal straw, and other grass fibres, most of which are composed of cellulose, hemicelluloses, lignin, waxes, and several water-soluble compounds, where cellulose, hemicelluloses, and lignin are the major constituents. Vegetable fibres have been used as a reinforcement of plastics and composites due to advantages such as lower density and good mechanical properties, as well as their economical and environmental advantages (Schmidt and Laurindo 2010; Debiagi et al. 2011).

If one is to consider cassava bagasse as potential polymer filler, it is important to know about its composition because, apart from containing cellulose and hemicelluloses, it also contains a high amount of starch, a natural polymer that has a high polarity due to the presence of large amounts of hydroxyls in its macromolecules, which interact with lignocellulosic fibres, resulting in improved mechanical properties (Corradini et al. 2008).

Low-density polyethylene has been studied as a composite matrix owing to its significant material flexibility, strength and durability (Kuila et al. 2011). In the literature, several natural fibres, such as coconut fiber, cellulose pulp fiber, doum palm fiber and banana stem fibre have been used to reinforce the low-density polyethylene (Brahmakumar et al. 2005; Sdrobiş et al. 2012; Khan et al. 2013). The objective of the present study was to evaluate the feasibility of using cassava bagasse in composites.

\section{MATERIALS AND METHODS}

Cassava bagasse samples were collected directly from two industrial plants, one in Paraná State (PR) and another in São Paulo State (SP). The samples were coded PR and SP, respectively. The PR was brought moist from the factory in Paraná and was transported from the processing plant at room temperature $\left(25^{\circ} \mathrm{C}\right)$ for around four hours, then frozen at $-18^{\circ} \mathrm{C}$ and kept until the use. This PR sample was dried in the laboratory using a circulating oven at $50^{\circ} \mathrm{C} / 72 \mathrm{~h}$, whereas the SP sample was dried in the industrial plant and collected as a dry flour (the drying of previously squeezed bagasse in a filter press was performed in a steam jacketed industrial dryer). The dried bagasse samples were ground (IKA Universal mill model M 20, Staufen, Germany) and sieved to obtain fine flour $(<250 \mu \mathrm{m})$. The selection of the two industrial plants was based on the fact that one of them had an industrial-scale bagasse drying system and the other was a well qualified factory with a good reputation and which donated the sample.

\section{Chemical composition of the bagasse samples}

The chemical composition of the bagasse samples was determined for moisture, protein, fibre, mineral residue and lipids (AOAC 2000). Starch content was assessed after enzymatic hydrolysis and glucose quantification (Demiate et al. 2001). Total carbohydrates were calculated by difference; all the assays were carried out in three repetitions.

\section{Colour of dried bagasse samples and composite specimens}

The colour measurements were carried out by 
employing a Hunter lab Miniscan EZ spectrophotometer (Hunter Associates Laboratory, Reston, VA, USA), considering the $\mathrm{L}^{*}, \mathrm{a}^{*}$ and $\mathrm{b}^{*}$ parameters, where $\mathrm{a}^{*}$ was the red $\left(+\mathrm{a}^{*}\right)$ to green colour $\left(-a^{*}\right)$; $b^{*}$ was the yellow $\left(+b^{*}\right)$ to blue $\left(-b^{*}\right)$ colour; L was the luminosity, from white $(\mathrm{L}=100)$ to black ( $\mathrm{L}=0)$ (Harder 2007). Both the dried bagasse powder and the composite specimens were analysed.

\section{Atomic force microscopy}

The samples were observed using a Shimadzu SPM 9600 (Shimadzu Corporation, Kyoto, Japan) equipment, which was able to produce threedimensional surface images of several kinds of materials. The non-contact AFM technique was employed and the samples were analysed at room temperature after being densely compacted in the conditions for the samples to be spread directly onto a sticking tape fixed on an AFM sample holder (Juszczak 2003).

\section{Scanning electron microscopy of the composite specimens}

The fractured surface of the composite specimens was also observed using the SEM technique (Shimadzu, EDX SS-550, Kyoto, Japan) after immersion in liquid nitrogen (Kaewtatip and Thongmee 2013).

\section{X-ray diffraction of bagasse}

The X-ray diffractograms were collected in a Rigaku Ultima IV (Rigaku, Tokyo, Japan) machine with $\mathrm{CuK} \alpha(\lambda=1.544 \AA)$ radiation at 40 $\mathrm{kV}$ and $20 \mathrm{~mA}$ (Beninca et al. 2008). The analysis was carried out at $20^{\circ} \mathrm{C}$ in a $2 \theta$ angle range of 7$30^{\circ}$ with a measuring period of $5 \mathrm{~s} / 2 \theta$.

\section{FTIR spectroscopy of the bagasse}

The FTIR spectra were produced using a Shimadzu FT-IR 8400 (Shimadzu, Kyoto, Japan) spectrophotometer in the region of 4000 to 700 $\mathrm{cm}^{-1}$, with the samples properly dispersed in $\mathrm{KBr}$ pellets as described elsewhere (Demiate et al. 2000).

\section{Differential scanning calorimetry (DSC) of bagasse}

In this analysis, $2.0 \mathrm{mg}$ of sample (dry basis) was weighed in aluminium sample pans and distilled water was added (1:6, starch: water), resulting in a dispersion that rested for $1 \mathrm{~h}$ for equilibrium. The pans were closed with proper lids in order to prevent water loss during the heating. The DSC device (Q-200, TA Instruments, New Castle, USA) was programmed for heating at $10^{\circ} \mathrm{C} \mathrm{min}^{-1}$ rate, from 30 to $95^{\circ} \mathrm{C}$. The equipment was calibrated with indium standard $(99.99 \%$, melting point of $\left.156.6^{\circ} \mathrm{C}, \Delta \mathrm{H}=28.56 \mathrm{~J} \mathrm{~g}^{-1}\right)$. Sealed aluminium pans were used (sample and reference). Endothermic curves with the correspondent onset and peak temperatures were produced, as well as the transition enthalpies $\left(\mathrm{J} \mathrm{g}^{-1}\right)$ (Vatanasuchart et al. 2005).

\section{Sorption isotherms of the bagasse}

Sorption isotherms were made according to Moraes et al. (2007). The samples of cassava bagasse had their moisture values equilibrated at $45^{\circ} \mathrm{C} / 48 \mathrm{~h}$ in a circulating oven. Approximately $1.0 \mathrm{~g}$ of sample was weighed in a small aluminium foil container and kept in hermetic glass recipients, which had different relative humidity resulted by $\mathrm{H}_{2} \mathrm{SO}_{4} \quad(\mathrm{~d}=1.84) \quad$ solutions at different concentrations $(5,10,20,30,40,50,55,60$ and $70 \% \mathrm{v} / \mathrm{v}$ ), and a recipient with distilled water. The hermetic glass recipients were kept at constant temperatures $\left(20\right.$ and $\left.30^{\circ} \mathrm{C}\right)$ in $\mathrm{BOD}$ incubators (BOD AL 200 American Lab, Charqueada, SP, Brazil) for 20 days. These samples were weighed daily in an analytical balance (ADA 210/C, Adam Equipment, Danbury CT, USA), presenting constant weight at the end of the period.

Moisture on dry basis was calculated by using equation 1:

$\mathrm{Xdb}=$ remaining water / dry matter

The sorption isotherms were drawn using Statistica 5.0 (Statsoft, Tulsa, OK, USA) software and using the Halsey model for adjustment. The constants (A and B) were obtained by linear regression (Quasi-Newton method) using the software (Statistica 5.0), choosing the best fit model by considering the $\mathrm{R}^{2}$ value. The Halsey adjustment was defined by equation 2 :

$$
X=\left[-\frac{A}{\ln \left(a_{w}\right)}\right]^{1 / B}
$$

Where:

$\mathrm{a}_{\mathrm{w}}=$ water activity (decimal); $\mathrm{A}$ and $\mathrm{B}=$ Halsey adjustment parameters; $\mathrm{X}=$ equilibrium moisture content in dry basis. 
Testing cassava bagasse in composite production, single-screw extruder processing The composites were produced using two bagasse samples in different amounts in a matrix of lowdensity polyethylene (Braskem, PB 681, Braskem, $\mathrm{SP}$, Brazil), with a fluidity index of $3.8(\mathrm{~g} / 10 \mathrm{~min})$, for obtaining composites with modified characteristics. The mixtures were made with 10 , 20 and $30 \%$ of cassava bagasse, using a total of six different types of composites. The composites were produced in a single-screw extruder (Ciola ME-30, Ciola, SP, Brazil) that was kept at $160^{\circ} \mathrm{C}$ and $50 \mathrm{rpm}$. The composites were produced in strip form and cooled in a gutter with flowing water; they were then cut into small pellets. These pellets were dried in a circulating oven (TE 394/2, TECNAL, SP, Brazil) at $60^{\circ} \mathrm{C} / 24 \mathrm{~h}$ to remove the moisture and to avoid mould growing on the surface. After drying, the pellets were stored in hermetic flasks.

\section{Obtaining the composite samples}

The composite pellets were processed in a plastic injection moulding machine (Boy-55M, Dr. Boy
GmbH \& Co., Neustadt-Fernthal, DE). The mould was kept at room temperature by continuous cooling with flowing water. The average dimensions of the specimens were $60 \mathrm{~mm}$ length, $9 \mathrm{~mm}$ width and $4 \mathrm{~mm}$ thickness for all the studied samples.

\section{Mechanical tests}

The composite samples were evaluated with a Shimadzu universal testing machine (AG-I, Shimadzu, Kyoto, Japan) for ultimate strength and elasticity modulus. The tests were carried out with 12 tie-shaped specimens for each composite formulation and the operating conditions were: test velocity $5 \mathrm{~mm} \mathrm{~min}^{-1}$ and maximum load $9,500 \mathrm{~N}$ (ASTM D 638, 1999).

\section{RESULTS AND DISCUSSION}

\section{Physicochemical characterisation of cassava bagasse}

Table 1 shows the physicochemical characteristics of the cassava bagasse samples.

Table 1 - Chemical composition of cassava bagasse ( $\% \mathrm{~m} / \mathrm{m}$, moist basis).

\begin{tabular}{cccccccc}
\hline Samples & Moisture & Ash & Protein & Fibre & Starch & Lipids & Carbohydrates $^{*}$ \\
\hline $\mathbf{( P R})$ & $7.15^{\mathrm{a}}$ & $2.43^{\mathrm{a}}$ & $1.89^{\mathrm{a}}$ & $42.93^{\mathrm{a}}$ & $42.70^{\mathrm{b}}$ & $0.11^{\mathrm{a}}$ & 2.66 \\
$\mathbf{( S P )}$ & $5.57^{\mathrm{b}}$ & $1.93^{\mathrm{b}}$ & $1.92^{\mathrm{a}}$ & $42.20^{\mathrm{a}}$ & $46.90^{\mathrm{a}}$ & $0.17^{\mathrm{a}}$ & 1.31 \\
p-ANOVA** $^{*}$ & $<0.001$ & $<0.001$ & 0.72 & 0.14 & $<0.001$ & 0.09 & - \\
\hline
\end{tabular}

*carbohydrates were calculated by difference. $* *$ Fisher Test.

The results of the physicochemical characterisation of the two bagasse samples were close to those previously reported by Pandey et al. (2000). However, there were some differences, which might have been related to different cassava cultivars, as well as to the production region and climate, harvest time and industrial processing technology (Chavalparit and Ongwandee 2009), among other factors. Besides starch, the bagasse samples presented high amounts of fibre, as expected for this type of plant material. The other components, mainly ash, protein and lipids, were only found in low amounts.

Colour of the bagasse samples and of the composite specimens

As the two samples considered in this study were visually different in colour, which was measured using a spectrophotometer. The $\mathrm{L}^{*}, \mathrm{a}^{*}$ and $\mathrm{b}^{*}$ parameters are shown in Table 2. The SP sample had the lowest luminosity, which might have been associated with the industrial drying conditions. The $a^{*}$ value indicated red colour $(a+)$ whereas the $b^{*}$ value indicated yellow colour $(b+)$. The results for the two samples as shown in Table 2 indicated a red colour tendency for the PR sample. For the $\mathrm{b}^{*}$ parameter, all the samples had a tendency to yellow colour, with the highest value for the PR sample.

Table 2 - DSC Gelatinisation, Colour parameters, NCAFM $\left(r_{a}\right)$ results of cassava bagasse.

\begin{tabular}{|c|c|c|c|c|c|c|c|c|}
\hline \multirow{2}{*}{ Samples } & \multicolumn{4}{|c|}{ DSC Gelatinisation } & \multicolumn{3}{|c|}{$\begin{array}{c}\text { Colour } \\
\text { parameters }\end{array}$} & \multirow{2}{*}{$\begin{array}{c}\text { NC- } \\
\text { AFM } \\
r_{a}\end{array}$} \\
\hline & $\begin{array}{l}\mathbf{T}_{\text {onset }} \\
/{ }^{\circ} \mathbf{C}\end{array}$ & $\begin{array}{l}\mathbf{T}_{\text {peak }} \\
/{ }^{\circ} \mathbf{C}\end{array}$ & $\begin{array}{c}\mathbf{T}_{\text {endset }} \\
/{ }^{\circ} \mathbf{C}\end{array}$ & $\begin{array}{l}\Delta \mathbf{H}_{\text {gel }} \\
/ \mathbf{J ~ g ~ g}^{-1}\end{array}$ & $\mathbf{L}$ & $* \mathbf{a}$ & $*_{\mathbf{b}}$ & \\
\hline (PR) & 59.54 & 68.11 & 71.0 & 10.7 & 83.79 & 17.9 & 13.0 & 45.98 \\
\hline (SP) & - & - & - & - & 57.43 & 6.23 & 2.77 & - \\
\hline
\end{tabular}


The composite specimens were also evaluated and the results were in accordance with the respective bagasse samples employed for producing the extruded material. For the highest bagasse concentrations $(30 \% \mathrm{~m} / \mathrm{m})$, the $\mathrm{L}, \mathrm{a}^{*}$ and $\mathrm{b}^{*}$ values for the samples SP and PR were 27.38 and 35.03, 3.55 and 7.11 and 5.83 and 11.50 , respectively.

\section{Microscopic analysis}

\section{Atomic Force Microscopy}

The NC-AFM technique enabled to obtain threedimensional surface images of the particles that formed the bagasse samples, as well as of the starch granules, and it was also possible to evaluate the mean rugosity of the samples. Figure 1 (A-B) showed that the image from the PR bagasse sample was similar to cassava starch, which could be explained by their drying
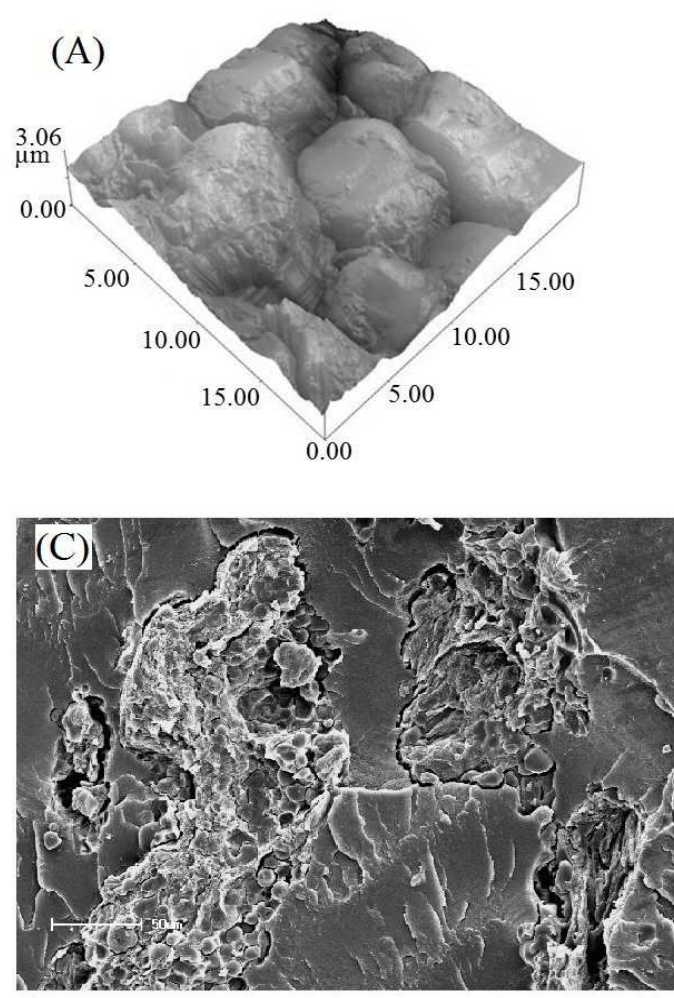

conditions and high starch content. Table 2 also shows the rugosity (ra) values for the PR bagasse sample. In this study, with the selected sample preparation and the available equipment, it was not possible to calculate the rugosity of the bagasse sample coded as SP due to its high fibre content, which was associated with the more severe drying technique and which made the sample pellet surface become excessively rough and irregular.

\section{Scanning electron microscopy}

The SEM images (Figs. 1C-D) of the extruded composite specimens showed starch granules inside the polyethylene matrix, and in most cases, the distribution was not homogenous. This was expected due to the fact that native starch granules were hydrophilic.
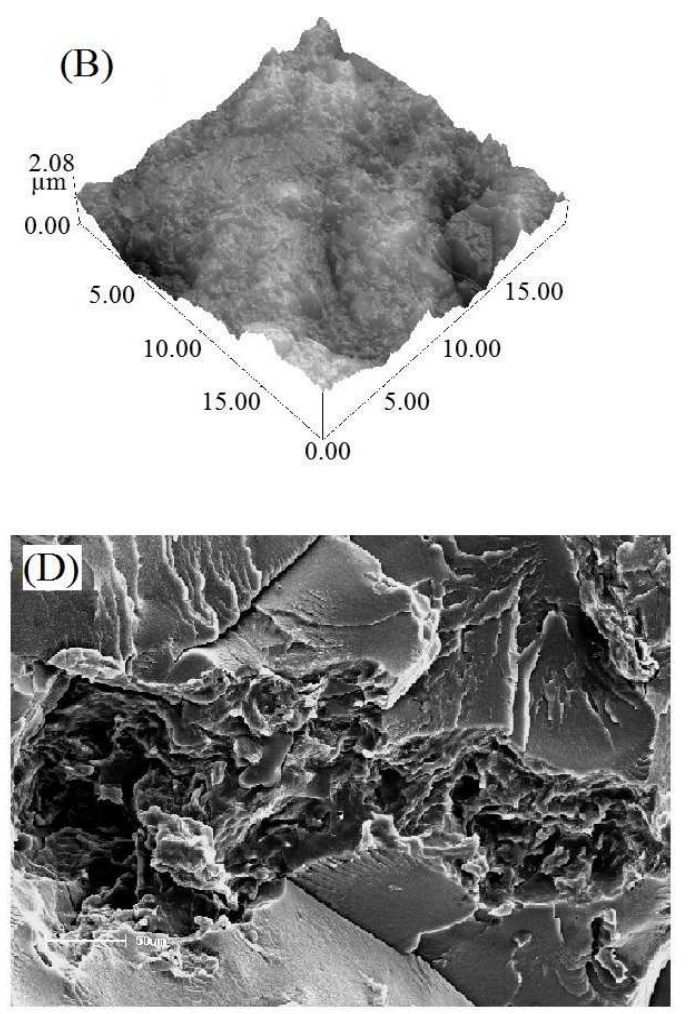

Figure 1 - Microscopic analysis: (A) and (B) NC-AFM of cassava bagasse samples, PR and SP respectively; (C) and (D) SEM of composite specimen samples.

\section{X-ray diffractograms}

Starch is stored in the plants as semi-crystalline granules arranged in concentric layers (Larsson 1991). X-ray diffractrometry permits the identification of crystallinity in starchy samples. Starch granules are present in high amounts in cassava bagasse and they present relative crystallinity (between 15 to $45 \%$ ), which is related to the presence of amylopectin. The X-ray diffractrogram of cassava starch classified it as Atype, presented peaks at $2 \theta$ angle in $15.3^{\circ}, 17.1^{\circ}$, $18.2^{\circ}$ and $23.5^{\circ}$ (data not shown). The bagasse 
sample coded as PR (Fig. 2) had a similar pattern to that of the cassava starch, described as A-type, which was related to the high starch contents $(46.9 \% \mathrm{~m} / \mathrm{m})$ of the bagasse sample as well as similar drying procedures.

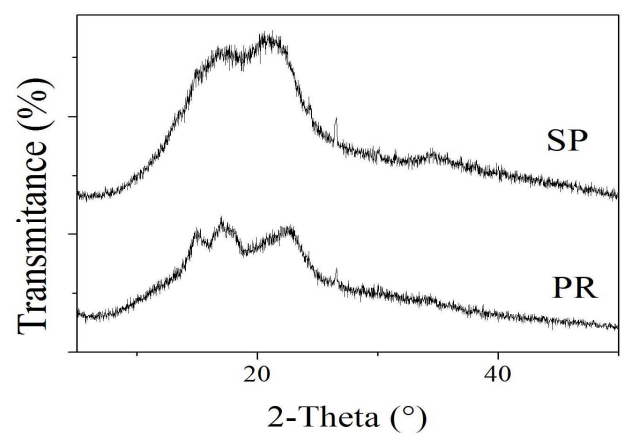

Figure 2 - X-ray diffraction of cassava bagasse samples.

The bagasse sample identified as SP presented a different behaviour, which was related to the severe industrial drying conditions that also made this sample darker than the PR sample. The diffractogram from the SP sample (Fig. 2) showed a loss of crystallinity and consequent structural disruption of the starch granules, indicating that the thermal treatment promoted starch gelatinisation. Starch gelatinisation is related to the loss of birefringence, or loss of structural organisation, and for cassava starch, this phenomenon occurred in a range from 60 to $70^{\circ} \mathrm{C}$ (Sangseethong et al. 2009). Heating the starch present in cassava bagasse in the presence of high water content causes the rupture of hydrogen bonds, which weakens the granular structure.

\section{Mid-infrared spectroscopy (FT-IR)}

As reported by Van Soest et al. (1995a), crystalline ordered regions in the starch granules absorbed in $1,047 \mathrm{~cm}^{-1}$ whereas their amorphous counterpart absorbed in the region of $1,022 \mathrm{~cm}^{-1}$. Peaks between 1,080 and $1,110 \mathrm{~cm}^{-1}$ are attributed to $\mathrm{C}-\mathrm{O}, \mathrm{C}-\mathrm{C}$ and $\mathrm{O}-\mathrm{H}$ stretching (Goodfellow et al. 1990; Van Soest et al. 1995b). These absorbance peaks are represented by amylose and amylopectin, which are rich in the above chemical bonds. The FTIR spectra confirmed the high amount of starch in the cassava bagasse samples. Maia et al. (2011) reported that peaks at 3,300 $\mathrm{cm}^{-1}$ were due to hydroxyl stretching, which was always abundant in polysaccharides. At 2,900 $\mathrm{cm}^{-1}$, C-H stretching is also present in polysaccharides.
Peaks close to $1,730 \mathrm{~cm}^{-1}$ are related to carbonyl groups and may indicate, in the specific case of bagasse samples, their conservative condition, as this peak is absent in natural starch (Fringant et al. 1996) and is present only in certain types of acidic or oxidised modified starches, with the presence of carbonyl groups. This carbonyl peak was present in the bagasse samples, although it was unexpected. The acidity values of the bagasse samples were measured and expressed in lactic acid as 0.04 and $0.34 \%(\mathrm{w} / \mathrm{w})$ for the PR and SP samples, respectively. The SP and PR samples presented an absorbance peak that might have been associated with the presence of a carboxyl group at $1,730 \mathrm{~cm}^{-1}$, suggesting the presence of organic acids due to bad conservation of the samples after industrial starch extraction and before drying.

As this material has a very low commercial interest for the cassava starch processors, it is not treated with care and is stored in bad conditions at high temperatures. All the samples presented peaks at $1,656-1,640 \mathrm{~cm}^{-1}$, which was related to the interaction of water with fibre and starch in the bagasse (Vercelheze et al. 2012). The FTIR spectra showed high similarity between the bagasse samples (Fig. 3).

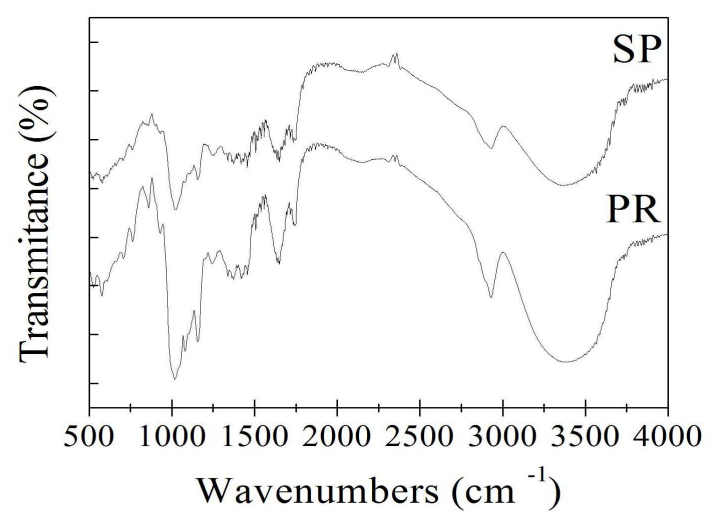

Figure 3 - Infrared spectra of cassava bagasse samples.

\section{Thermal Analysis - differential scanning calorimetry (DSC)}

The DSC analysis showed a pattern that was related to the granular starch content in the PR bagasse, as the temperature of gelatinisation for cassava starch was around $65^{\circ} \mathrm{C}$, in accordance with the literature (Sangseethong et al. 2009).

When heated in a controlled way, the industrial bagasse sample PR (Fig. 4) also presented a pattern that resembled cassava starch. The peak 
temperature was $68.22^{\circ} \mathrm{C}$, with onset at $59.57^{\circ} \mathrm{C}$, and final at $71.09^{\circ} \mathrm{C}$, with enthalpy variation of $9.61 \mathrm{~J} \mathrm{~g}^{-1}$ (Table 2). The starch content of this bagasse sample was $46.90 \%$ (Table 1). The SP sample (Fig. 4) was dried in industrial conditions at higher temperatures and did not present gelatinisation peaks due to the fact that this phenomenon had already occurred during drying. The bagasse colouration was also darker, indicating that a severe drying condition had been adopted (Table 2), with luminosity ( $\left.\mathrm{L}^{*}\right)$ of $57.43 \%$, the lowest among all the samples. It is noteworthy that cassava bagasse drying is mandatory for thermal behaviour as it contains a high concentration of starch as well as high water content and gelatinisation takes place during the processing.

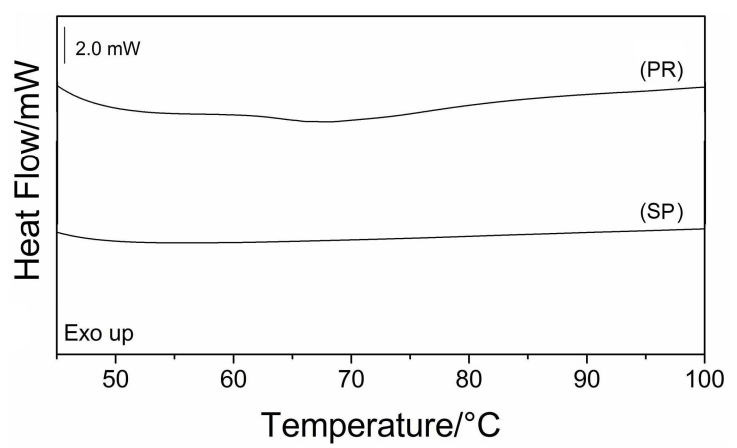

Figure 4 - DSC analysis of cassava bagasse samples.

\section{Sorption isotherms}

The PR and SP bagasse samples were evaluated for moisture equilibrium (dry basis moisture) and, as expected, it increased in relation to increasing Aw (Fig. 5) due to the hygroscopic behaviour of the material. When the temperature was increased, the equilibrium moisture decreased (Fig. 5). This kind of behaviour was also found by Cassini et al. (2006) for soybean protein and it was related to the fact that as temperature increased, the vapour pressure in the samples also increased, accelerating moisture transfer from the inside to the surface of the material. The energetic molecular state changes with higher temperatures, decreasing the attractive forces, which results in a lower sorption degree, or lower hygroscopicity in a relative humidity (Jamali et al. 2006).

The PR sample had the lowest value for equilibrium moisture, whereas the SP bagasse had the highest for both the temperatures (20 and $30^{\circ} \mathrm{C}$ ). After 20 days of experiments, the SP and PR samples exhibited fungal growth (at atmosphere, with sulphuric acid concentrations of 0 and 10\%) and consequently, deterioration of these samples occurred due to high water availability that was absorbed from the environment.

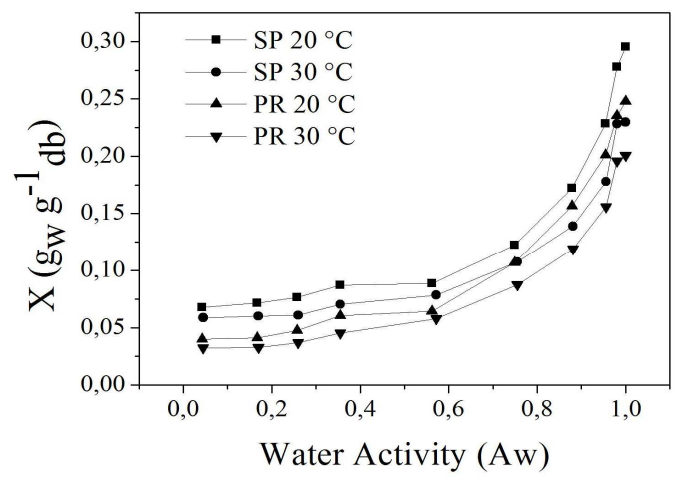

Figure 5 - Water activity of cassava bagasse samples.

The isotherms were adjusted using the Halsey model, which was well suited to the foods and starchy materials, such as cassava, corn, potato and wheat (Kurozawa et al. 2005). The Halsey model was dependent on two parameters (A and B) and best fitted for the cassava bagasse samples with the highest R-value (Table 3). The lowest Rvalue of 0.9813 was for the SP sample.

Table 3 - Halsey parameters for moisture sorption isotherms for the bagasse samples $\left(\mathrm{R}^{2}\right.$ is the correlation coefficient).

\begin{tabular}{|c|c|c|c|c|}
\hline Samples & Model & $\mathbf{R}^{2}$ & $\mathbf{A}$ & B \\
\hline & IALSEY & 9902 & 0.00153 & 2.2540 \\
\hline & & & & 2.1817 \\
\hline & HAL & 0.9813 & 0.00077 & 2.8614 \\
\hline (S) & HALSEY & 0.9869 & 0.00039 & 2.9545 \\
\hline
\end{tabular}

\section{Mechanical properties of the composites}

In general, the fibre components of composites increase mechanical resistance due to the entanglement mechanism with polymeric chains and the due to the fact that an adhesion between them is provided. The blends were produced in a single-screw extruder, which was not efficient regarding homogeneity due to the lack of dispersive and distributive mixture. Due to this feature, the tensile assay revealed that all the composites broke easier than pure low-density polyethylene. This could have been related to nucleation and crack propagation due to incomplete mixture of the constituents of the composite during the injection of the specimens. 
This could be observed in Fig. 1 (C-D) where the bagasse distribution was not homogenous. The mechanical assays for the elasticity modulus and ultimate tensile strength are shown in Table 4 . The ultimate tensile strength is the maximum value of stress verified in a stress-strain curve, being the ultimate resistance to tensile effort. The highest value was found for the neat low-density polyethylene. In the composites, there was a decrease in the value of ultimate tensile strength as the content of bagasse increased, corroborating the observation of nucleation and crack propagation mechanism due to inefficient mixture.

Table 4 - Results obtained from the mechanical test of composites with low-density polyethylene (LDPE) and bagasse (PR or SP).

\begin{tabular}{|c|c|c|}
\hline Composite & $\begin{array}{c}\text { Elasticity } \\
\text { modulus } \\
\text { (Fisher Test ) } \\
\end{array}$ & $\begin{array}{c}\text { Ultimate } \\
\text { strength } \\
\text { (Kruskal -Wallis ) }\end{array}$ \\
\hline $\begin{array}{l}\text { LDPE } 100 \% \\
\text { bagasse } 0 \%\end{array}$ & $104.86^{\mathrm{e}}$ & $11.34^{\mathrm{a}}$ \\
\hline $\begin{array}{l}\text { LDPE } 90 \% \\
\text { bagasse PR } 10 \%\end{array}$ & $131.90^{\mathrm{d}}$ & $8.95^{\mathrm{ab}}$ \\
\hline $\begin{array}{l}\text { LDPE } 80 \% \\
\text { bagasse PR } 20 \%\end{array}$ & $157.68^{c}$ & $8.24^{\mathrm{bc}}$ \\
\hline $\begin{array}{l}\text { LDPE } 70 \% \\
\text { bagasse PR } 30 \%\end{array}$ & $171.33^{b}$ & $7.64^{b c}$ \\
\hline $\begin{array}{l}\text { LDPE } 90 \% \\
\text { bagasse SP } 10 \%\end{array}$ & $135.25^{\mathrm{d}}$ & $9.88^{\mathrm{ab}}$ \\
\hline $\begin{array}{l}\text { LDPE } 80 \% \\
\text { bagasse SP } 20 \%\end{array}$ & $168.34^{\mathrm{b}}$ & $8.61^{\mathrm{b}}$ \\
\hline $\begin{array}{l}\text { LDPE } 70 \% \\
\text { bagasse SP 30\% }\end{array}$ & $186.28^{\mathrm{a}}$ & $7.52^{\mathrm{c}}$ \\
\hline $\begin{array}{l}\mathrm{p}-\mathrm{ANOVA} / \\
\text { Kruskal -Wallis }\end{array}$ & $<0.001$ & $<0.001$ \\
\hline
\end{tabular}

However, the composites with added cassava bagasse were stiffer than pure low-density polyethylene, which was demonstrated by the higher elasticity modulus values that resulted from increasing the levels of added bagasse. For both the samples, the high fibre content resulted in better mechanical properties compared to pure polyethylene. However, the SP bagasse sample presented the highest value, which could have been related to its higher starch content (46.90\%). As mentioned above, mechanical properties depend upon adhesion between polymeric matrix and the filler added: fibre and starch bagasse, in this case. Considering the differences in the polarity of both (nonpolar low-density polyethylene and polar bagasse) and the low mixture efficiency due to the processing in a single-screw extruder, one would expect a lack of adhesion between these phases. However, the higher presence of starch can improve the adhesiveness between bagasse and the matrix, improving the mechanical properties, along with high fibre values. Furthermore, due to the way it was processed, the SP bagasse had a rough and irregular surface (Fig. 1B), which enabled the bagasse to increase the adhesion in the matrix. The elastic modulus had an increase above $75 \%$ when $30 \%$ SP bagasse was used.

Some reported disadvantages of using biofibres in composites are their low resistance to processing temperatures (Ornaghi 2012), variability in mechanical properties, high sensitivity to environmental conditions (temperature and relative humidity), dependence on soil conditions, harvesting time, and post-harvest processing. Some advantages of natural fibres are the fact that they are less abrasive than the artificial fibres commonly used as reinforcement; they are biodegradable materials and represent a new source of income for rural populations. They have low density and high deformability and relatively low-cost if compared to currently employed reinforcements.

\section{CONCLUSION}

The cassava bagasse presented different starch contents and high fibre values, which was related to the processing conditions, as well as colour and appearance. These differences were also confirmed through the instrumental analysis of AFM, DSC and colorimetry. The X-ray diffractograms showed that the PR sample presented A-type pattern, whereas the SP bagasse sample did not present the typical pattern due to its drying conditions, which promoted starch gelatinisation. FTIR spectra of the tested bagasse samples were similar to the cassava starch spectrum, except for the absorbance peak at $\sim 1,730 \mathrm{~cm}^{-1}$, which was typical of a carboxylic group. The DSC enabled the confirmation of starch gelatinisation in the SP bagasse sample, which was related to its drying conditions, as well as the granular starch presence in the PR sample. Sorption isotherms allowed acceptable conditions to be established (temperature and relative humidity) for the storage of the cassava bagasse. Considering a temperature of between 20 and $30^{\circ} \mathrm{C}$, the maximum relative humidity for good 
preservation would be $60 \%$. The utilisation of cassava bagasse in the composites with lowdensity polyethylene matrix could be possible, with structural reinforcement acting as filling. This could avoid using potentially toxic synthetic conventional materials and could provide environmental advantages.

\section{ACKNOWLEDGMENTS}

The authors are grateful to the Araucaria Foundation (Fundação Araucária) - Support for Scientific and Technology Development of Paraná State - and to the National Council for Scientific and Technological Development $(\mathrm{CNPq})$ for financial support.

\section{REFERENCES}

Akil HM, Omar MF, Mazuki AAM, Safiee S, Ishak ZAM, Abu Bakar A. Kenaf fibre reinforced composites: A review. Mater Design. 2011; 32(8-9): 4107-4121.

AOAC. Official methods of analysis. J. AOAC Int. 17st ed. Gaithersburg: MD, 2000.

Ashori A, Wood-plastic composites as promising green-composites for automotive industries. Bioresource Technol. 2008; 99: 4661-4666.

Ashori A, Nourbakhsh A. Characteristics of wood-fibre plastic composites made of recycled materials. Waste Manage. 2009; 29(4): 1291-1295.

ASTM D 638-99 - Standard test method for tensile properties of plastics. Annual Book of ASTM, Philadelphia, PA: ASTM, 1999.

Beninca C, Demiate IM, Lacerda, LG, Carvalho Filho MAS, Ionashiro M, Schnitzler E. Thermal behaviour of corn starch granules modified by acid treatment at 30 and $50^{\circ}$ C. Eclet Quím. 2008; 33(3):13-18.

Brahmakumar M, Pavithran, Pillai RM. Coconut fibre reinforced polyethylene composites: effect of natural waxy surface layer of the fibre on fibre/matrix interfacial bonding and strength of composites. Compos Sci Technol. 2005; 65(3): 563-569.

Cassini AS, Marczak LDF, Noreña CPZ. Water adsorption isotherms of texturized soy protein. $J$ Food Eng. 2006; 77: 194-199.

Chavalparit O, Ongwandee M. Clean technology for the tapioca starch industry in Thailand. J Clean Prod. 2009; 17: 105-110.

Corradini E, Agnelli JAM, Morais LC, Mattoso LHC. Estudo das propriedades de compósitos biodegradáveis de amido/glúten de milho/glicerol reforçados com fibras de sisal. Polímeros. 2008; 18(4): 353-358.
Debiagi F, Mali S, Grossmann MVE, Yamashita F. Biodegradable foams based on starch, polyvinyl alcohol, chitosan and sugarcane fibres obtained by extrusion. Braz Arch Biol Technol. 2011; 54(5): 1043-105.

Demiate IM, Konkel FE, Pedroso RA. Enzymatic determination of starch in doce de leite using dialysis. Ciencia Tecnol Alimen. 2001; 21: 339-342.

Demiate IM, Dupuy N, Huvenne JP, Wosiacki G, Cereda MP. Relationship between baking behavior of modified cassava starches and starch chemical structure determined by FTIR spectroscopy. Carbohydr Polym. 2000; 42(2): 149-158.

FAO. World Crop Production Statistics. Food nutr. 2010.

Fringant C, Desbrières J, Rinaudo M. Physical properties of acetylated starch-based materials: relation with their molecular characteristics. Polymer. 1996; 3(13): 2663-267.

Goodfellow BJ, Wilson RHA. Fourier Transform Ir Study Of The Gelation Of Amylose And Amylopectin. Biopolymers. 1990; 30: 1183-1189.

Harder MNC, Canniatti-Brazaca SG, Arthur V. Quantitative evaluation by a digital colorimeter of the color of the egg of laying hens fed with annatto (Bixa orellana). Rev Port Ciênc Vet. 2007; 102(563-564): 339-342.

Jamali A, Kouhila M, Ait Mohamed L, Jaouhari JT, Idlimam A, Abdenouri N. Sorption isotherms of Chenopodium ambrosioides, leaves at three temperatures. J Food Eng. 2006; 72(1): 77-84.

Juszczak L. Surface of triticale starch granules-NCAFM observations. Electr J Pol Agric Univer. 2003; $8(8)$.

Kaewtatip K, Thongmee J. The effects of cross-linked starch on the properties of thermoplastic starch. Mater Design. 2013; 45: 586-589.

Khan AGM, Shams AMS, Kabir MR, Gafur MA, Terano M, Alam M S. Influence of chemical treatment on the properties of banana stem fiber and banana stem fiber/coir hybrid fiber reinforced maleic anhydride grafted polypropylene/low-density polyethylene composites. J Appl Polym Sci. 2013; 128: 1020-1029.

Kuila T, Bose S, Hong CE, Uddin ME, Khanra P, Kim $\mathrm{NH}$, Lee JH. Preparation of functionalized graphene/linear low density polyethylene composites by a solution mixing method. Carbon. 2011; 49(3): 1033-1037.

Kurozawa LE, El-Aouar ÂA, Murr FEX. Obtenção de isotermas de dessorção de cogumelo in natura e desidratados osmoticamente. Cienc Tecnol Aliment. 2005; 25(4): 828-834.

Larsson K. Structure of the starch granule - a curved crystal. Acta Chem Scand. 1991; 45: 840-843. 
Maia TF, Mulinari DR. Influência do tolueno na modificação química das fibras de bagaço de cana-deaçúcar. Ano VI, n. 16, Volta Redonda: Cadernos UniFOA; 2011.

Maieves HA, Oliveira DC, Bernardo C, Müller CMO, Amante ER. Microscopy and texture of raw and cooked cassava (Manihot esculenta Crantz) roots. $J$ Texture Stud. 2012; 43: 164-173.

Maieves HA, Oliveira DC, Frescura JR, Amante, ER. Selection of cultivars for minimization of waste and of water consumption in cassava starch production, Ind Crop Prod. 2011; 33:224-228.

Moraes MA, Rosa GS, Pinto LAA. Equilibrium isotherms of chitin: heat of desorption determination. Braz J Food Technol. 2007; 10: 212-219.

Ozen E, Kiziltas A, Kiziltas EE, Gardner DJ. Natural fibre blend-nylon 6 composites. Polym Composite. 2013; 34(4): 544-553.

Ornaghi HL, Da Silva HSP, Zattera AJ, Amico SC. Dynamic mechanical properties of curaua composites. J Appl Polym Sci. 2012; 125: 110-116.

Pandey A, Soccol CR, Nigam P, Soccol VT, Vandenberghe LPS, Mohan R. Biotechnological potential of agro-industrial residue II: cassava bagasse. Bioresource Technol. 2000; 74: 81-87.

Rosenthal DM, Slattery RA, Miller RE, Grennan AK, Cavagnaro TR, Fauquet CM, et al. Cassava aboutFACE: Greater than expected yield stimulation of cassava (Manihot esculenta) by future $\mathrm{CO} 2$ levels. Glob Chang Biol. 2012; 18: 2661-2675.

Sangseethong K, Lertphanich S, Sriroth K. Physicochemical properties of oxidized cassava starch prepared under various alkalinity levels. Starch - Stärke. 2009; 61: 92-100.

Satyanarayana KG, Guimarães JL, Wypych F. Studies on lignocellulosic fibers of Brazil. Part I: Source, production, morphology, properties and applications. Compos Appl Sci Manuf. 2007; 8(7): 1694-1709.

Schmidt VCR, Laurindo JB. Characterization of foams obtained from cassava starch, cellulose fibres and dolomitic limestone by a thermopressing process. Braz Arch Biol Technol. 2010; 53(1): 185-192.
Sdrobiş A, Darie RN, Totolin M, Cazacu G, Vasile C. Low density polyethylene composites containing cellulose pulp fibers. Compos Part B-Eng. 2012; 43 (4): 1873-1880.

Sriroth K, Chollakup R, Chotineeranat, S, Piyachomkwan K, Oates CG. Processing of cassava waste for improved biomass utilization. Bioresource Technol. 2000; 71: 63-69.

Teixeira EM, Pasquini D, Curvelo AAS, Corradini E, Belgacem MN, Dufresne A. Cassava bagasse cellulose nanofibrils reinforced thermoplastic cassava starch. Carbohydr Polym. 2009; 78(3): 422-431.

Teixeira EM, Curvelo AAS, Corrêa AC, Marconcini JM, Glenn GM, Mattoso LHC. Properties of thermoplastic starch from cassava bagasse and cassava starch and their blends with poly (lactic acid). Ind Crop Prod. 2012; 37(1): 61-68.

Utsumi Y, Tanaka M, Morosawa T, Kurotani A, Yoshida T, Mochida K., et al. Transcriptome Analysis Using a High-Density Oligomicroarray under Drought Stress in Various Genotypes of Cassava: An Important Tropical Crop. DNA Res. 2012; 19: 335-345.

Van Soest JJG, Hulleman SHD, Wit D, De Vliegenhart JFG. Crystallinity in starch bioplastics. Ind Crop Prod. 1995a; 5: 11-22.

Van Soest JJG, Vliegenthart JFG, Tournois H, Wit D. Short-range structure in (partially) crystalline potato starch determined with attenuated total reflectance Fourier-transform IR spectroscopy. Carbohydr Res. 1995b; 279: 201-214.

Vatanasuchart N, Naivikul O, Charoenrein S, Sriroth K. Molecular properties of cassava starch modified with different UV irradiations to enhance baking expansion. Carbohydr Polym. 2005; 61(1): 80-87.

Vercelheze AES, Fakhouri FM, Dall'antônia LH. Properties of baked foams based on cassava starch, sugarcane bagasse fibres and montmorillonite. Carbohydr Polym. 2012; 87(2): 1302-1310.

Received: October 24, 2013; Accepted: July 28, 2014. 